\title{
Avaliação da cultura de feijão (Phaseolus vulgaris cv carioquinha) em solo contaminado por metais pesados, utilizando técnicas de microscopia eletrônica de varredura e espectrometria por dispersão de energia
}

Paulo Régis Viana Leite*
João Vicente Zampieron**

* Universidade do Estado de Minas Gerais, campus da Fundação de Ensino Superior de Passos (FESP-UEMG), Faculdade de Engenharia de Passos (FEP), graduando em agronomia. Passos, Minas Gerais (BR). E aluno de graduação do curso Técnico em Meio Ambiente do Instituto Federal de Educação, Cuiência e Tecnologia do Sul de Minas Gerais, campus Muzambinho. pauloregisvianaleite@hotmail.com. (035)91456840. Rua Tico Tico, 20, Bairro Nossa Senhora das Graças, Passos Minas Gerais, CEP 37.902-394.

**Universidade do Estado de Minas Gerais, campus da Fundação de Ensino Superior de Passos (FESP-UEMG), Faculdade de Engenharia de Passos (FEP), professor pesquisador. Passos, Minas Gerais, (BR). jovizam@hotmail.com. (035) 3522-9503. Rua Capitólio, 648, Bairro Muarama, Passos, Minas Gerais, CEP 37.902-336.

\section{Resumo}

Foi utilizada a cultura de feijão carioquinha (Phaseolus vulgaris) para determinar a sua sensibilidade em solos contaminados por metais pesados de origem industrial e doméstica. Para tanto, foram construídos quatro canteiros, sendo três com solos previamente contaminados e um canteiro como referência. Através de análises de espectrometria por energia dispersiva (EDS), pôde-se identificar os elementos absorvidos pela cultura de feijão. A análise via microscopia eletrônica de varredura (MEV), cuja função é evidenciar possíveis impactos na superfície das plantas, não apresentou qualquer alteração. A análise EDS evidenciou que a cultura de feijão não absorve metais pesados, sendo seletiva quanto à absorção de nutrientes em quaisquer de suas partes.

Palavras chaves: Metais pesados. Caracterização. Meio ambiente. Poluentes.

\section{Introdução}

Pesquisas sobre os efeitos tóxicos de metais pesados em plantas têm demonstrado que existe uma forte dependência do nível de concentração do elemento disponível requerido como nutriente. Se tal concentração de um determinado elemento ultrapassar os níveis requeridos como nutriente, ele pode causar fitotoxidade, inibindo com isso muitas funções metabólicas, resultando em crescimento retardado de raiz e caule, causando clorose em folhas jovens e, inclusive, impedindo a absorção de outros elementos essenciais às plantas. Tais estudos têm mostrado que o stress causado por metais pesados é um dos maiores problemas que afeta a produtividade das plantas na agricultura, mas, por outro lado, pode vir a ser uma ferramenta de manipulação genética para alterar características indesejáveis nestes vegetais (YADAV, 2010).

Estudos relacionados ao grau de tolerância ao chumbo foram reportados por Wierzbicka (1999), tendo observado de forma comparativa, entre diversas plantas, que aquelas que se formaram a partir do bulbo apresentam uma tolerância superior às desenvolvidas a partir de sementes. Tal fato foi relacionado à capacidade de transporte de grandes quantidades de chumbo da raiz ao bulbo e de armazenagem deste metal neste último, demonstrando assim, forte adaptação em solo altamente poluído. 
$\mathrm{Na}$ Irlanda foram desenvolvidos trabalhos levando em consideração a concentração de cobre e chumbo, verificando-se que o chumbo concentrou-se, principalmente, nas raízes das monocotiledôneas. O propósito principal do estudo foi comparar as concentrações de cobre e chumbo nas raízes e brotos de uma quantidade de espécies de plantas localizadas em pântanos, ao longo do estuário Suir. $O$ chumbo foi escolhido pelo fato de se apresentar em elevada concentração nestas regiões, enquanto o cobre foi escolhido como indicador de poluição industrial e doméstica (FITZGERALD et al., 2003).

$\mathrm{Na}$ natureza o cromo aparece em sistemas biológicos na forma de íons $\mathrm{Cr}$ (III) e íons Cr (VI), sendo que este último se apresenta como a forma mais tóxica e sua concentração aparece de forma mais intensa nas raízes do que nas folhas. Estudos em couve-flor (Brassica oleracea L, var. Bottrytis cv. Maghi) têm demonstrado que os elementos $\mathrm{Cr}$, Co e $\mathrm{Cu}$ causam uma diminuição da concentração de clorofila, podendo resultar na inibição de transporte de elétron fotossintético. A concentração desses metais em couve-flor pode causar efeitos prejudiciais em seres humanos e também em ruminantes (CHATTERJEE; CHATTERJEE, 2000).

Algumas espécies de plantas têm sido usadas como sensores para detectar a ecotoxidade do solo. An et al. (2004) verificaram que a germinação das sementes e o crescimento das plantas são bons indicadores da presença de metais, podendo ser utilizados como fator de bioacumulação (BAF) para metais específicos.

Metais pesados como o cromo e o chumbo são relatados como fortes poluidores do solo e, potencialmente, tóxicos aos organismos vivos. Muitos estudos demonstraram que esses elementos influenciam na germinação de sementes e no crescimento das plantas, sendo o chumbo prontamente assimilado por elas quando disponível no solo (AN, 2006).

A fitotoxidade do níquel foi investigada em plantas como cevada (Hordeum vulgare cv. Regina) e tomate (Lycopersicon esculentum), cultivadas em 16 tipos de solos europeus. Tal estudo mostrou que o crescimento do caule do tomate foi mais sensível à toxidade do níquel do que a raiz da cevada. Esta diferença é devido à forma de assimilação que cada cultivar apresenta. Tal resultado pode ser usado como indicador de risco da contaminação pelo níquel no ambiente terrestre (ROONEY et al, 2007).

Para minimizar os impactos produzidos pelos rejeitos, pesquisadores têm realizado estudos para inclusão dos resíduos na indústria da construção civil, fazendo vista à minimização dos impactos ambientais por eles gerados. Escórias de alto forno são utilizadas na construção civil como um dos componentes do concreto, fazendo parte de programas governamentais, que visam critérios de aplicabilidade nesta indústria, onde sua utilização obedece a rígidos aspectos ambientais (MROUEH; WAHLSTROM, 2002; CARVALHO et al., 2008 ).

De acordo com Li et al. (2009), existem poucos dados sobre a toxidade do cobalto nas plantas e sua influência sobre a toxidade no solo. Estudos realizados por esses autores, utilizando cevada e tomate, mostraram uma forte inibição no crescimento do caule nessas culturas, o que sugere que tais plantas podem ser consideradas um indicador de solos contaminados por este elemento.

O mercúrio é um dos elementos preocupantes quanto à contaminação de solos, visto que pode ser assimilado por plantas e animais. Estudos neste sentido foram conduzidos utilizando-se mostarda indiana (Brassica juncea L.) submetida à elevada concentração deste elemento ( $\left.\geq 2 \mathrm{mgL}^{-1}\right)$. Pôde-se observar uma significativa redução na biomassa e na quantidade de água contida nas folhas. Estudos de microscopia indicaram que a elevada concentração de mercúrio nas plantas mudou significativamente a estrutura das folhas. Assim, a alta acumulação de mercúrio na mostarda indiana, especialmente nas raízes, indicou que esta pode ser uma potencial candidata para a fitofiltração de águas contaminadas e fitoestabilização de solos contaminados (SHIYAB et al., 2009).

Pesquisas desenvolvidas em solos destinados à agricultura e contaminados por metais pesados mostraram sérias influências negativas sobre a saúde humana. Devido ao rápido desenvolvimento de determinadas regiões da China, estas apresentaram, nas áreas produtoras de vegetais elementos como $\mathrm{Cd}, \mathrm{Hg}, \mathrm{As}, \mathrm{Pb}, \mathrm{Cr}, \mathrm{Cu}, \mathrm{Zn}$ e Ni. Os resultados deste estudo mostraram que as concentrações de $\mathrm{Hg}$ e $\mathrm{Pb}$ eram provenientes de atividades antropogênicas, tais como fumaças oriundas, tanto dos veículos, quanto de origem industrial, além da água de irrigação proveniente de rios e lagos contaminados; enquanto o $\mathrm{Cd}$, $\mathrm{Cu}$ e $\mathrm{Zn}$ eram provenientes do uso de produtos agroquímicos, e o $\mathrm{Cr}$, 
As e Ni eram provenientes de suas rochas de origem. Nas áreas produtoras, as que utilizaram estufas tinham maior quantidade de $\mathrm{Cd}$, cuja origem foi atribuída ao uso de rochas fosfáticas e fertilizantes orgânicos. Quanto aos solos de campos abertos, apresentaram uma maior quantidade de contaminação por $\mathrm{Cu}$, provenientes do uso intensivo de agroquímicos (LIU et al., 2011).

\section{Materiais e Métodos}

Foram montados 4 canteiros, assim distribuídos: mistura solo/escória de níquel; mistura solo/chumbo; mistura solo/rejeitos de pilha, e um canteiro referência (testemunho) nas seguintes proporções: canteiro 1, contendo $28 \mathrm{~kg}$ de solo e $12 \mathrm{~kg}$ de escória de níquel; canteiro 2, contendo 40 $\mathrm{kg}$ de solo e $125 \mathrm{~mL}$ de solução de $\mathrm{Pb}+\mathrm{HCl}$, canteiro 3, contendo $40 \mathrm{~kg}$ de solo com $425 \mathrm{~g}$ de pilha e bateria e $125 \mathrm{~mL}$ de $\mathrm{HCl}$, dissolvido em $1250 \mathrm{~mL}$ de água, e por fim o canteiro 4 (referência), contendo $40 \mathrm{~kg}$ de solo.

O desenvolvimento das plantas foi acompanhado desde a germinação até a fase adulta. Foram medidas as temperaturas locais e o índice de luminosidade, através de um termômetro digital, marca TFA, modelo Kat.Nr.30.1026, de luxímetro, modelo MLM-1010, marca Minipa e um paquímetro marca WESTERN, modelo DC-60. As medidas de altura foram tomadas a partir de uma fita métrica marca STARRET, modelo T12-3

As plantas adultas foram colhidas e levadas a uma estufa de secagem, onde foram desidratadas à temperatura de $70^{\circ} \mathrm{C}$, sendo em seguida moídas em moinho marca Tritumaq. Posteriormente foi retirada uma amostra e levada a uma evaporadora, sendo recoberta com ouro para a realização de análises via microscopia eletrônica de varredura (MEV) e, posteriormente, analisadas via EDS, para detectar os elementos absorvidos pelas suas partes (caule, folhas, raiz e frutos).

\section{Resultados e Discussão}

Os resultados foram tomados em relação às análises que apresentaram maior significância quanto à absorção de algum elemento que faz parte, ou não, dos nutrientes da planta. As plantas demonstraram um alto grau de seletividade para absorção de elementos, mesmo em solos contaminados.

No canteiro contendo chumbo misturado ao solo, a raiz foi a parte da planta que mostrou uma assimilação diferente em relação às outras partes, como ilustrado na figura 1. Verificou-se uma assimilação considerável do $\mathrm{Al}$, que é um elemento abundante nos solos de Cerrado, bioma predominante desta região. Tal elemento apresenta-se disponível na forma livre ou na forma $\mathrm{Al}^{3+}$ no solo, dependendo do pH. Geralmente ocorre em baixas concentrações em solos com pH abaixo de 5,5, o que é típico da maioria dos solos de Cerrado, sendo considerado um elemento que inibe a absorção de nutrientes, além de ser um elemento mineral tóxico às plantas.

A constatação da maior quantidade de $\mathrm{Al}$ na raiz da planta, em relação aos demais elementos, pode ser um indicador de solo com baixo $\mathrm{pH}$, além de poder estar relacionado a algum mecanismo de seletividade da planta, na presença de elementos tóxicos. Fitzerald et al. (2003) desenvolveram trabalhos levando em consideração a concentração de cobre e chumbo nas raízes e brotos de uma quantidade de espécies de plantas localizadas em pântanos, ao longo do estuário Suir. Verificaram que o chumbo concentrou-se, principalmente, nas raízes das monocotiledôneas. Porém, em dicotiledôneas, especialmente leguminosas, nenhum dado foi encontrado, sugerindo que outros estudos sejam realizados, no intuito de confirmar as suspeitas de que, em presença de elementos tóxicos no solo, haja uma elevação na absorção de Al pela planta. 
Figura 1. EDS em raiz de feijão em solo contendo $\mathrm{Pb}$.

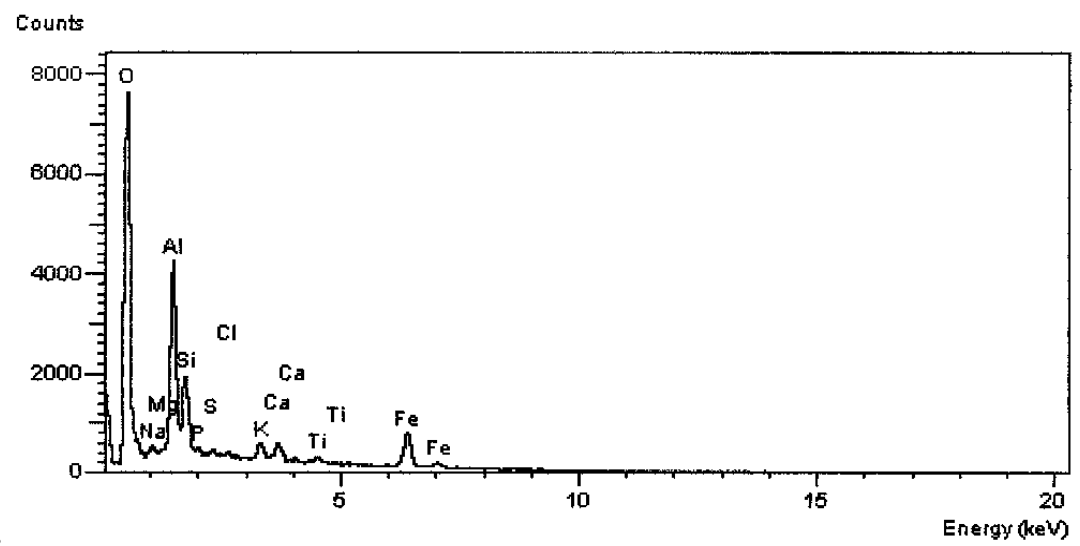

Fonte: Elaboração própria.

Pôde-se constatar que no canteiro contendo a mistura solo e escória, as partes da planta que manifestaram uma absorção mais expressiva foram o caule e as folhas (figura 2 e 3). Os elementos Ca e o $\mathrm{K}$ foram absorvidos de forma mais significante que os demais elementos. O Ca é um elemento que é absorvido pelas plantas na forma bivalente $\left(\mathrm{Ca}^{2+}\right)$ e tem diversas funções como: elemento estrutural, que se localiza em alta concentração na lamela média das paredes celulares, equilibra a relação cátions/ânions, atua na regulação osmótica, atua na divisão e extensão celular.

O K é um elemento importante para os processos metabólicos. De acordo com Kerbauy (2004) este elemento se apresenta como $\mathrm{K}^{+}$, que é um íon monovalente de pequeno raio iônico, cuja absorção é altamente seletiva e acoplada aos processos metabólicos, apresentando elevada mobilidade na planta em todos os níveis: no interior das células, entre células individuais, entre tecidos e no transporte a longa distância via xilema e floema. Além disso, apresenta ainda importantes funções nas células e tecidos das plantas como: relações hídricas, no alongamento celular, na fotossíntese, no transporte de açúcares no floema, entre outras funções, podendo ser um dos fatores que contribuiu para o vigor físico visivelmente observado no caule da planta. Nota-se claramente que estes dois elementos foram absorvidos em maior quantidade em canteiros contendo a escória de níquel.

Figura 2. EDS em caule de feijão em solo contaminado de escória.

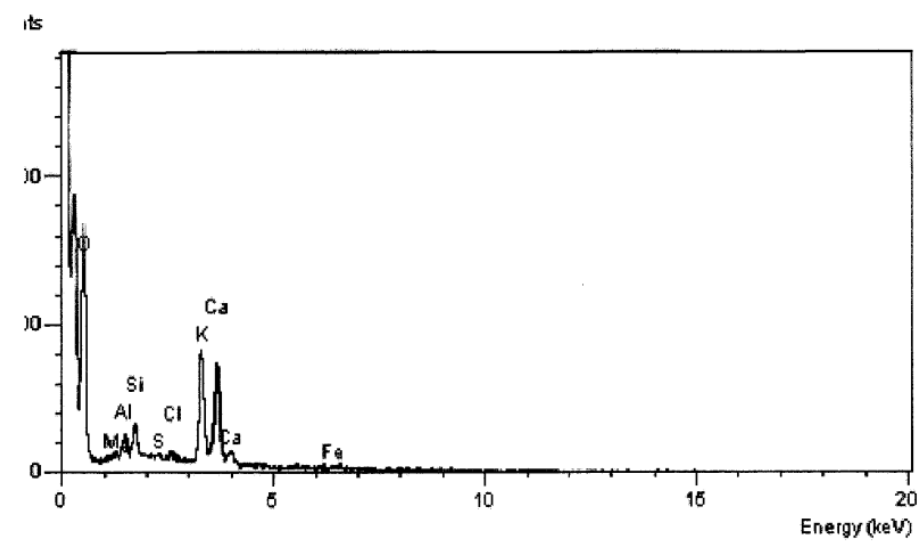

Fonte: Elaboração própria.

A Figura 3 mostrou um elevado índice de cálcio absorvido pelas folhas, sendo um elemento essencial à planta, como anteriormente mencionado. Outro elemento que se sobressaiu foi o $\mathrm{Si}$, que tem funções extremamente importantes, como proteção da planta contra ataque de pragas e doenças. A sua presença nas folhas torna-se muito significativa pois elas são responsáveis pela reserva de nutrientes que, consequentemente, irão contribuir na formação de grãos. Pôde-se 
observar ainda um teor mais acentuado de Al, que é um elemento indicador de pH baixo do solo, considerado tóxico e forte inibidor do crescimento para as plantas.

Figura 3. EDS em folhas de feijão em solo contendo escória.

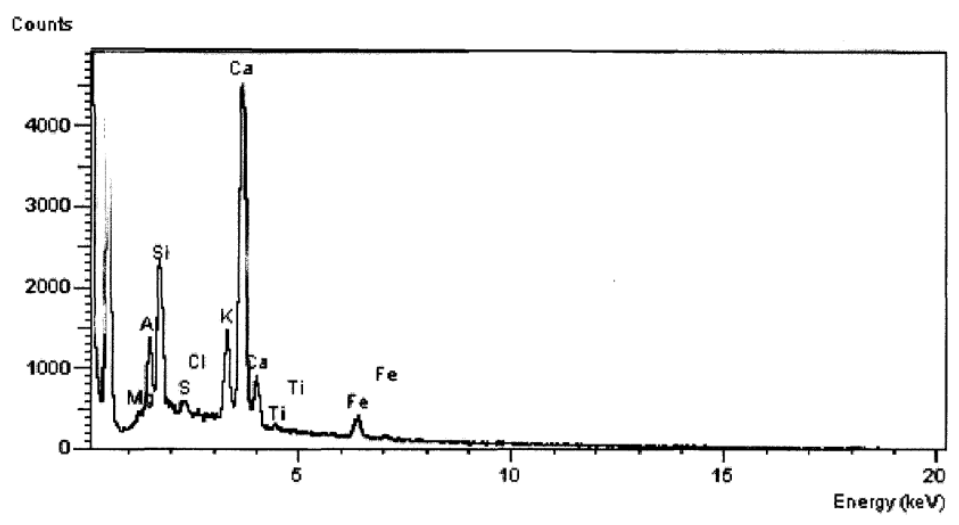

Fonte: Elaboração própria.

No canteiro contendo solo com rejeito de pilhas houve um significativo retardamento no crescimento vegetativo, levando as plantas à morte logo em seus primeiros estádios de vida, não chegando a atingir o estádio reprodutivo. Isto sugere uma forte inibição por parte dos elementos constituintes do rejeito de pilhas. Não houve uma parte da planta que apresentasse uma absorção mais expressiva em relação às outras. A raiz, que é a responsável pela absorção de nutrientes, tomada como exemplo, apresentou uma absorção bem homogênea, não se destacando nenhum elemento em quantidade significativa, conforme ilustrado na Figura 4.

Figura 4. EDS em raiz de feijão em solo contendo rejeito de pilha.

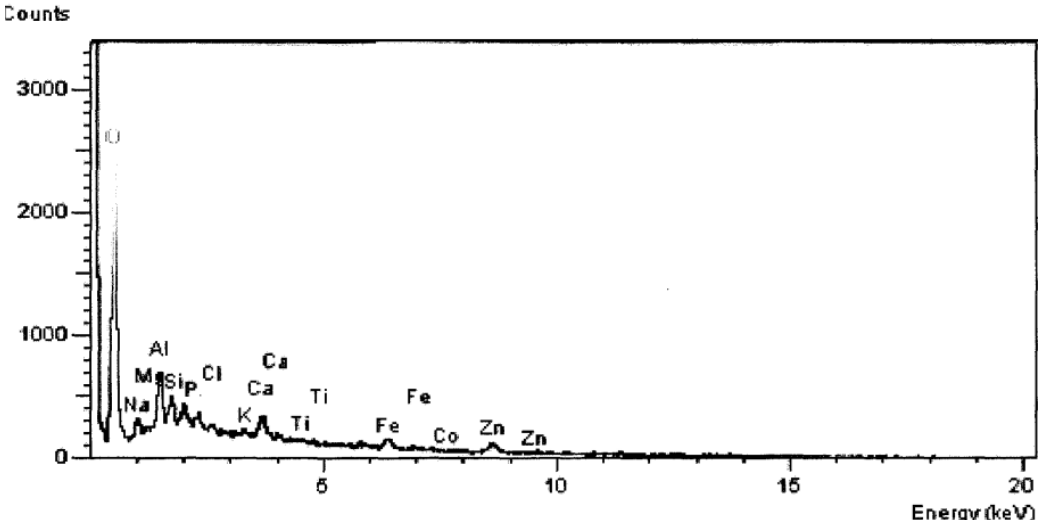

Fonte: Elaboração própria.

O Al aparece em destaque como elemento em maior quantidade absorvida em relação aos demais elementos, sugerindo mais uma vez possível correlação com a presença de metais pesados no solo. Kerbauy (2004) destaca que a natureza do efeito benéfico do Al no crescimento das plantas não está clara, mas existem substanciais evidências de que há um efeito indireto, na maioria das vezes relacionado com a competição (ou precipitação) com outros elementos minerais presentes em quantidades tóxicas, principalmente $\mathrm{P}, \mathrm{Zn}$ e $\mathrm{Cu}$.

Nas análises via microscopia de varredura (Figuras 5, 6 e 7), pôde-se observar que a superfície da planta não mostrou qualquer alteração, tais como rachaduras ou nenhum desenvolvimento das partes da planta, o que pode ser um indicativo que a planta é altamente adaptada, inclusive, em solo alterado em sua composição química, constituindo-se num fator positivo, visto que o feijão é uma cultura popular. 
Figura 5. MEV do fruto de feijão.

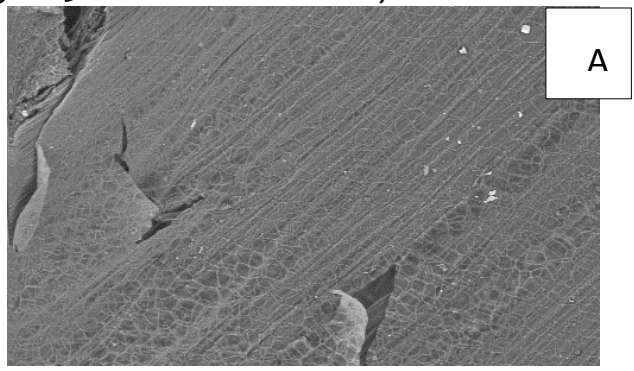

(A) solo padrão, (B) solo contendo 30\% escória. Fonte: Elaboração própria.

Figura 6. MEV do caule.
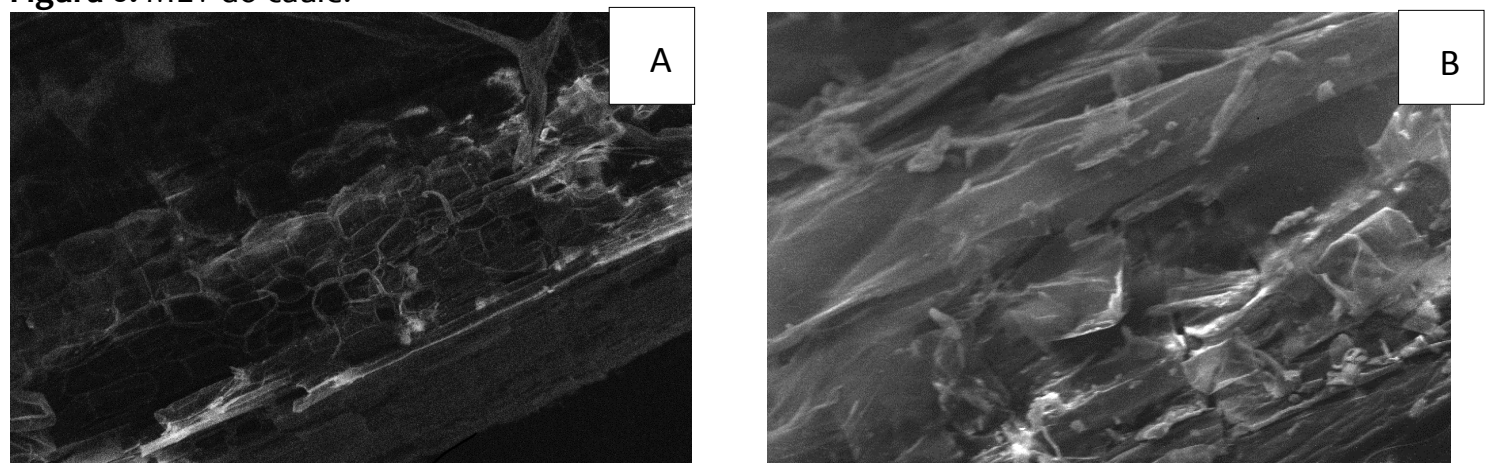

(A) solo padrão, (B ) solo contendo 30\% de escória. Fonte: Elaboração própria.

Figura 7. MEV da raiz.

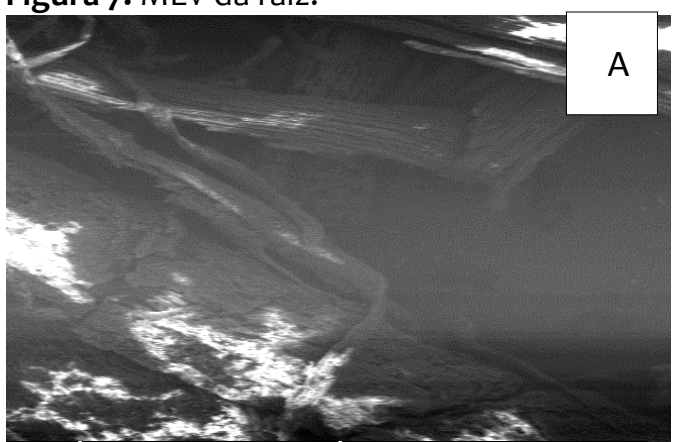

(A) solo padrão, (B) solo contendo 30\% de escória. Fonte: Elaboração própria.

\section{Conclusões}

A análise via EDS evidenciou que a cultura de feijão não absorveu metais pesados, mostrando-se seletiva quanto à absorção desses elementos em suas partes.

As plantas submetidas a solos com diferentes contaminações não exibiram danos em sua superfície, como verificado pelas análises via MEV.

Em canteiros com presença de metais pesados houve uma absorção maior do Al, indicando um possível mecanismo de competição com outros elementos presentes em quantidades tóxicas, tais como $\mathrm{P}, \mathrm{Zn}$ e $\mathrm{Cu}$.

Em canteiros com escória de Ni houve destaque para a absorção de $\mathrm{K} \mathrm{e} \mathrm{Ca}$, mostrando que tal tipo de rejeito provavelmente disponibilize tais elementos em grandes quantidades. 
A cultura do feijão apresentou alta resistência em solos com diferentes formas de contaminação, o que demonstra que é uma cultura de alta seletividade quanto à absorção de nutrientes.

\title{
Agradecimentos
}

Os autores agradecem ao CNPq pela bolsa PIBIC do aluno Paulo Regis Viana Leite e à Empresa Homeopassos pelo apoio durante o desenvolvimento do presente trabalho.

\section{Evaluation of the bean crop carioquinha (Phaseolus vulgaris L.) in soil contaminated by heavy metals using techniques of scanning electron microscopy and energy dispersive spectrometry.}

\begin{abstract}
We used a culture of beans carioquinha (Phaseolus vulgaris) to determine its sensitivity in soils contaminated by heavy metals from industry and domestic. We used three plots of previously contaminated land and a plot as a reference. Through analysis of energy dispersive spectrometry (EDS) can raise the elements absorbed by the crop of beans. The analysis via scanning electron microscopy (SEM) whose function is to show potential impacts on plant surfaces, showed no change. The EDS analysis showed that the cultivation of beans does not absorb heavy metals, being selective about the absorption of nutrients in any of its parts.
\end{abstract}

Key words: Heavy metals. Characterization. Environment. Pollutants.

\section{Referências bibliográficas}

AN, Y. J. Soil ecotoxicity assessment using cadmium sensitive plants. Enviromental Pollution, [s.l.], v. 127, n. 1, p. 21-26, jan. 2004.

AN, Y.J. Assessment of comparative toxicities of lead and copper using plant assay. Chemosphere, [s.l.] v. 62, n. 8, p. 1359-1365, mar. 2006.

AN, Y.J. et al. Combined effect t of copper, cadmium, and lead upon Cucumis sativus growth and bioaccumulation. Science of the Total Environment, [s.l.], v. 3, n. 1-3, p. 85-93, jun. 2004.

CARVALHO, M. T.; FRANCKLIN JUNIOR, I.; ZAMPIERON, J. V. Estudo preliminar da interação de escória de níquel em argamassa de cimento Portland. Boletim Técnico da Faculdade de Tecnologia de São Paulo, São Paulo, v. 25, p. 3, 2008.

CHATTERJEE, J.; CHATTERJEE, C. Phytotoxicity of cobalt, chromium and copper in cauliflower.

Environmental Pollution, [s.l.], v. 109, n. 1, p. 69-74, jul. 2000. 
FITZGERALD, E. J. et al. Copper and lead concentrations in salt marsh plants on the Suir Estuary, Ireland. Environmental Pollution, [s.l.], v. 123, n. 1, p.67-74, mai. 2003.

KERBAUY, G. B. Fisiologia vegetal. Rio de Janeiro: Guanabara Koogan, 2004.

LI, H. F. et al. Phytotoxicity and bioavailability of cobalt in a range of soils. Chemosphere, [s.l.], v.75, n. 7, p. 979-986, mai. 2009.

LIU, P. et al. Analysis of Heavy metal sources for vegetable soils from Shandong province, China. Agricultural Sciences in China, [s.l.], v. 10, n. 1, p. 109-119, jan. 2011.

MROUEH, M.; WAHLSTROM, M. By-products and recycled materials in earth construction in Finland an assessment of applicability. Resources, conservation and Recycling, [s.l.], v. 35, n. 1-2, p.117129, abr. 2002.

ROONEY, C. P.; ZHAO, F. J.; MCGRATH, S. P. Phytotoxicity of nickel in a range of European soils: Influence of soil properties, Ni solubility and speciation. Environmental pollution, [s.l.], v. 145, n. 2, p. 596-605, jan. 2007.

SHIYAB, S. et al. Phytotoxicity of mercury in Indian mustard (Brassica juncea L.). Ecotoxicology and Environmental Safety, [s.1.], v. 72, n. 2, p 619-625, fev. 2009.

YADAV, S. K. Heavy metals toxicityin plants: an overview on the role of glutathione and phytochelatins in heavy metal stress tolerance of plants. South African Journal of Botany, [s.l.], v.76, n. 2, p. 167-179, abr. 2010.

WIERZBICKA, M. Comparison of lead tolerance in Allium cepa wilh other plant species. Environmental Pollution, [s.1], v. 104, n. 1, p. 41-52, jan. 1999.

Histórico editorial

Recebido: 22/06/2012

Avaliação e copidesque: 16/07/2012 a 08/10/2012

Publicação aprovada: 30/10/2012 